Original article

\title{
The Research Domain Criteria (RDoC) and the historical roots of psychopathology: A viewpoint
}

\author{
Drozdstoy Stoyanov ${ }^{\mathrm{a}, *, 1}$, Diogo Telles-Correia ${ }^{\mathrm{b}, 1}$, Bruce N. Cuthbert ${ }^{\mathrm{c}}$ \\ a Department of Psychiatry and Medical Psychology, Research Complex for Translational Neuroscience, Medical University of Plovdiv, Bulgaria \\ ${ }^{\mathrm{b}}$ University of Lisbon, Clínica Universitária de Psiquiatria e Psicologia Médica, Faculdade de Medicina, Universidade de Lisboa, Lisbon, Portugal \\ ${ }^{\mathrm{c}}$ National Institute of Mental Health, USA
}

\section{A R T I C L E I N F O}

\section{Article history:}

Received 2 October 2018

Received in revised form 13 November 2018

Accepted 17 November 2018

Available online 21 January 2019

\section{Keywords:}

Psychiatric diagnosis

Psychiatric nosology

Research domain criteria

RDoC

\begin{abstract}
A B S T R A C T
In this article we aim at conceptual reconstruction of the historical background behind RDoC project. It incorporates some elements that have not heretofore been included in frameworks for psychopathology research. At the same time, however, RDoC - like any approach to mental illness - must grapple with longstanding challenges in addressing issues about the roles and relationships of mind, brain, and patients' reports in considering the nature of disorder. In this respect, the historical roots of psychopathology remain as relevant as ever.
\end{abstract}

(c) 2018 Elsevier Masson SAS. All rights reserved.
While the US National Institute of Mental Health (NIMH) Research Domain Criteria project (RDoC) represents an attempt to foster research that contributes to innovative precision diagnosis and treatment comparable to other areas of medicine, any new approach to psychiatric diagnosis must necessarily address issues that trace back to the very beginnings of psychiatry. Throughout the nineteenth century, psychiatry began to be identified as an autonomous medical specialty and to seek scientifically valid methods for classifying its disorders. For Philippe Pinel, known as the first psychiatrist, nosology should be based on clinical presentation (symptoms and clusters of symptoms) [1]. At the second half of the 19th century, driven by the euphoria of the search for neuroanatomical causes for neuro-psychiatric diseases, there was a concentration on the neurobiological basis of symptoms in psychiatric illness. For authors such as Wilhelm Griesinger, Carl Wernicke, and Alois Alzheimer, among others, "mental illnesses were diseases of the brain" as Griesinger famously stated [2].

Wernicke, while known for his work on aphasias, also attempted to formulate a general etiopathogenic model for mental illness. Having discovered that aphasia was associated with a localized lesion in a region of the brain, he believed that mental illness could also be determined by abnormalities in certain brain

\footnotetext{
* Corresponding author.

E-mail address: drozdstoy.stoyanov@mu-plovdiv.bg (D. Stoyanov).

1 The first and the second author have equal contribution to this paper.
}

regions. He thus created a "functional localistic model" and the "sejunction hypothesis" - that psychopathological symptoms originated from interruption ("sejunction") of associative connections in the brain [3]. In this view, there would be certain brain areas located in the subcortical, cortical and transcortical regions that were interconnected, and disruptions in their association could determine the onset of mental illness. This model was rooted in the anatomical studies of Theodore Meynert, who had emphasized the importance of connectional patterns in the neuropathology of the neurological and psychiatric symptoms [4].

The localizationist effort in psychopathology was complemented and enhanced by Karl Kleist, one of Wernicke's most prominent disciples, who contributed to the discovery of neuropathological findings associated with mental symptoms. At that time, neuropathology was investigated primarily based on the study of neuropsychological and neuropsychiatric consequences of cerebral lesions. By adopting this methodology, Kleist attributed certain locations in the brain to psychiatric symptoms, symptom groups, and even whole syndromes. He thus designed a brain-localization map according to an assumption of strict "localizationism" of all mental functions, analogous to the famous Brodmann and Von Economo neuroanatomical maps. According to some authors, Kleist's localizationism and Meynert-Wernicke's connectionism share many similarities to the results obtained with latest technologies such as fMRI and PET [5].

Thus, these models from psychiatrists of the nineteenthcentury transition argued that there could be a decomposition of mental symptoms into specific (and traceable) brain areas and 
their associations. However, the difficulty in finding a cause based on neuroanatomical findings (such as Alzheimer's disease) or infectious agents (as in syphilis) resulted in an epistemological crisis in psychiatry that moved the debate away from mechanistic explanations to clinical phenomenology.

With the marked development of neurosciences, there was a general tendency to include Psychology and Psychiatry close to the natural sciences, using exclusively their methods of investigation. It was in this context that, at the end of the 19th century, an important debate took place about the position of Psychology and Psychiatry and the Human Sciences in relation to the scientific method ("Methodenstreit") [6].

In response to the positivist posture of neuropsychiatry, another line of thought arose, arguing that the ontology (object) and epistemology (method) of the human sciences differ from those of the natural sciences. Among the authors who defended this view was the sociologist Max Weber, according to whom sociology needed a hybrid approach that was between the humanities and the natural sciences [6] Karl Jaspers followed a similar view, applied to psychiatry. According to him, it was necessary to reconnect psychiatric reality with the human sciences [7]. Jaspers argued also for determination of a scientific method for the collection and systematization of psychiatric signs and symptoms (phenomenology). Emil Kraepelin, Kurt Schneider, and Eugen Bleuler aspired essentially to the same direction: Diagnosis, prognosis, and treatment were based on the clinical presentation of the patients. Yet Kraepelin is also assumed to have been involved into the progress of the neuro-psychiatry, especially with the Nissl-Alzheimer tradition [1,8].

Psychiatric classification became even more indeterminate during the decades of psychodynamic theory, finally re-emerging as a significant issue in the 1970 s due to concerns about reliability and validity. A group of researchers from Washington University in St. Louis, recognizing the need to create rigorous diagnoses for research, proposed in 1972 a set of criteria for defining disorders (the so-called "Feighner Criteria") that included clinical description, follow-up studies, and delimitation from other disorders, family history, and laboratory studies. [9,2]. This group represented the new wave of so-called "neo-Kraepelinian" approaches to diagnosis, in recognition of Kraepelin's seminal ideas that the definition of a diagnostic category should take into account criteria related to clinical presentation and also to neurobiological findings. This work culminated in the 1978 paper by Spitzer, Endicott, and Robins promulgating the "Research Diagnostic Criteria" (RDC), expanding the set of diagnoses and introducing a more evidence-based and atheoretical view of psychiatry that served as the precursor to the DSM-III architecture [10].

The development of DSM-III has also been attributed to other indirect influences [11]. In his 1959 paper Carl Gustav Hempel [12] stressed that the two major requirements for a scientific classification are the (i) use of scientific vocabulary (descriptive terms and/or theoretical terms); and (ii) use of operational criteria. Although neither Hempel nor other positivists are mentioned, DSM-III is generally considered to follow a neopositivist style $[13,14]$. Hempel's influence on the elaboration of the ICD was acknowledged by Erwin Stengel, who was commissioned by WHO to make recommendations for a classification that would be most widely acceptable. Stengel wrote a paper in this regard in which he openly cited the contributions of Hempel [15]. Another author who is sometimes overlooked, but who played a key role in building the ICD-8 mental disorders section and its glossary, was Aubrey Lewis. His writings influenced the introduction of a descriptive-symptom based classification [16]

Given the advances in neuroscience and behavioral science in the period following the release of the DSM-IV, there was widespread anticipation that the DSM-5 would be based more strongly upon neurobiological criteria. To this end, an extensive series of scientific conferences was held to provide a scientific basis for the subsequent DSM revision process. In the event, however, in spite of some refinements of various criteria and alterations in some diagnoses, the document released as the DSM-5 was generally considered to be mildly evolutionary rather than radically divergent.

During this same period, staff at the NIMH also evaluated diagnostic studies emerging from multiple laboratories. Data from neuroimaging, genomics, behavioral science, and other fields increasingly indicated that the results generally failed to align with DSM diagnoses. Perturbations in the same neural systems (associated with fear, reward, cognitive processes, etc.) could be observed across multiple disorders, while not all patients in a given diagnostic category evinced the same response patterns. In other words, DSM categories represented heterogeneous syndromes rather than specific disease entities [17,18]. The data suggested that more tractable topics for study appeared to be particular aspects of behavioral, cognitive, or affective functioning that could increasingly be tied to particular neural systems, as suggested by basic behavioral and cognitive neuroscience studies with animal models or healthy human subjects.

One result of this perspective was a call in NIMH's 2008 strategic plan for new ways of studying mental illness based on dimensions of observable behavior and neurobiological measures, eventuating in the $\mathrm{RDoC}$ initiative. The intent was not to promulgate a new set of clinical categories that would serve as an alternative nosology to the DSM or the ICD (even on a test basis, as with the Research Diagnostic Criteria of the 1970s [10]. Rather, RDoC represents a framework for psychopathology research, proposing independent variables in experimental designs organized around functional constructs (e.g., fear, working memory, social withdrawal) rather than traditional categories such as schizophrenia or depression.

The framework was developed in a series of workshops and is comprised of major domains of functioning (e.g., reward systems, cognition), each with several subordinate functional constructs (e.g., attention and perception within cognition); the constructs are measured across multiple units of analysis, including circuit activity, behavior, and self-reports. [19] The framework is intended to be updated continually on the basis of new data, as reflected by recent revisions to multiple domains. [20].

The scientific approach for RDoC concords with the intellectual legacy of several aspects of classical neuropsychiatry, which is not surprising since any account of abnormal behavior must address issues regarding mind-brain relationships and how psychopathology is viewed and defined. For instance, there is a clear echo of the Meynert-Wernicke approach in the RDoC emphasis on circuit activity as a primary locus of dysregulated brain activity related to psychopathology. Further, several contemporary literatures have focused on particular brain areas per se (such as the basolateral nuclei of the amygdala or particular areas of the prefrontal cortex), reflecting Kleist's influence. One distinction from these historical views, however, is that RDoC adopts an integrative approach that places equal weight on behavioral and physiological measures so as to study relationships among the various units of analysis, rather than pursuing a purely reductionistic goal [21,22].

Further, it must always be borne in mind that symptoms are what bring patients to the clinic, and what they want ameliorated by treatment. So, the formulations of later phenomenologists such as Jaspers are also highly pertinent. However, RDoC departs from these classical authors in how symptoms are regarded - not merely as presenting complaints that partially index a broad syndromal illness, but as likely abnormalities in particular functions that (ideally) can be measured in terms of the extent of divergence from normal. 
As this statement implies, another major characteristic of RDoC concerns its emphasis on a dimensional approach to cognitive and motivational functions - not simply as an index of disorder severity, but to characterize the entire range of functioning, from normal to abnormal, on a population basis. The psychopathology that the alienists of the nineteenth century observed was so extreme that it was natural to infer diseases that were entirely distinct from normality. In contrast, contemporary research suggests that much psychopathology (such as internalizing and externalizing) can be placed along a continuum that ranges from marked abnormality to near-seamless overlaps with normal-range functioning; further, the Dutch psychiatrist Jim van Os has provided data along the same lines with respect to psychotic disorder [22]. RDoC eschews disorder definitions altogether, focusing instead on data that can support data-driven revisions to future versions of the DSM and the ICD that include quantitative, empirically-based cutpoints for disorders.

Befitting a research framework intended to promote new ideas and evolve continually, RDoC comprises a set of desiderata rather than prescriptive requirements - as reflected in a wide variety of research and comments. For instance, most studies explore RDoC constructs in the context of traditional disorder categories, and the relationship of categories or taxons to dimensions continues to be a matter for debate [23]. Comments regarding the RDoC framework also vary: While (as noted above) the majority of papers elaborating the RDoC framework emphasize the integration of multiple measures in analysis [19], other articles have a somewhat more reductionistic perspective [24,25] (although the latter can be read as an entreaty to include biological measures in etiology and diagnosis given the long history and continued prevalence of mentalistic concepts in psychiatry). Finally, any approach that incorporates laboratory tasks devised to measure various behavioral functions must address oft-encountered problems of modest reliability and convergent validity $[25,26]$; while passive monitoring, enhanced attention to inter- individual variability in task design, and computational phenotyping offer promising ways forward, measurement hurdles must be overcome to accelerate progress in precision diagnosis and treatment trials.

In conclusion, $\mathrm{RDoC}$ represents a blend of the old and the new. The project incorporates some elements that have not heretofore been included in frameworks for psychopathology research. At the same time, however, RDoC - like any approach to mental illness must grapple with longstanding challenges in addressing issues about the roles and relationships of mind, brain, and patients' reports in considering the nature of disorder. In this respect, the historical roots of psychopathology remain as relevant as ever.

\section{Conflicts of interest}

The authors report no financial conflicts of interest.

\section{References}

[1] Telles-Correia D, Sampaio D. Editorial: historical roots of psychopathology Front Psychol 2016;7:905, doi:http://dx.doi.org/10.3389/fpsyg.2016.00905.

[2] Telles-Correia D. The concept of validity throughout the history of psychiatry. J Eval Clin Pract 2017, doi:http://dx.doi.org/10.1111/jep.12750.

[3] Franzek E (1990) Influence of Carl Wernicke on Karl Leonard's Nosology. 23:277-281.

[4] Deacon T. Holism and associationism in neuropsychology: an anatomical synthesis. In: Perecman E, editor. Integrating theory and practice in clinical neuropsychology. Hillsdale, New Jersey: Lawrence Erlbaum Associates; 1989. p. $1-47$.

[5] Neumarker KJ, Bartsch AJ. Karl Kleist (1879-1960) - a pioneer of neuropsychiatry. Hist Psychiatry 2003;14(4):411-45.

[6] Telles-Correia D, Saraiva S, Gama Marques J. Jaspers' phenomenology. Folia Med (Plovdiv) 2018;60(3):373-80.

[7] Jaspers K. General psychopathology (Hamilton M Hoenig J, Trad.). Manchester: Manchester University Press; 1963.

[8] Hippius H, Neundörfer G. The discovery of Alzheimer's disease. Dialogues Clin Neurosci 2003;5(1):101-8.

[9] Feighner J, Robins E, Guze S, Woodruff R, Winokur G, Munos R. Diagnostic criteria for use in psychiatric research. Arch Gen Psychiatry 1972;26:57-63.

[10] Decker H. The making of DSM-III. Conclusion. NY: Oxford University Press: 2013. p. 309-32.

[11] Spitzer R, Endicott J, Robins E. Research diagnostic criteria. Arch Gen Psychiatry 1978;35:773-82.

[12] Hempel CG. Fundamentals of taxonomy. In: Sadler JS, Wiggins OP, Schwartz MA, editors. Philosophical perspectives on psychiatric diagnostic classification. Baltimore, MD: Johns Hopkins University Press; 1994. p. 315-32.

[13] Parnas J, Bovet P. Psychiatry made easy: operation(al)ism and some of its consequences. In: Kendler KS, Parnas J, editors. Philosophical issues in psychiatry III: the nature and sources of historical change. Oxford University Press; 2015. p. 190-212.

[14] Aragona M. Neopositivism and the DSM psychiatric classification. An epistemological history. Part 1: theoretical comparison. Hist Psychiatry 2013;24(2):166-79.

[15] Stengel E. Classification of mental disorders. Bull World Health Organ 1959;21:601-63.

[16] Fulford B, Thornton T, Graham G. Natural classifications, realism, and psychiatric science. In Oxford textbook of philosophy and psychiatry. Oxford University Press; 2006. p. 316-83.

[17] Hyman R. The diagnosis of mental disorders: the problem of reification. Ann Rev Clin Psychol 2010;6:155-79.

[18] Kapur S, Phillips M, Insel T. Why has it taken biological psychiatry so long to develop clinical tests and what to do about it? Mol Psychiatry 2012;17:1174-9.

[19] Kozak M, Cuthbert B. The NIMH research domain criteria initiative: background, issues, and pragmatics. Psychophysiology 2016;53:286-97.

[20] National Institute of Mental Health. Research domain criteria (RDoC). 2018. https://www.nimh.nih.gov/research-priorities/rdoc/index.shtml.

[21] Patrick C, Venables N, Yancey J, Hicks B, Nelson L, Kramer M. A constructnetwork to bridging diagnostic and physiological domains: applicaton to assessment of externalizing psychopathology. J Abnorm Psychol 2013;122:902-16.

[22] Guloksuz S, Van Os J. The slow death of the concept of schizophrenia and the painful birth of the psychosis spectrum. Psychol Med 2017;48:229-44.

[23] Haslam N, Holland E, Kuppens P. Categories versus dimensions in personality and psychopathology: a quantitative review of taxometric research. Psychol Med 2012;42:903-20.

[24] Insel T, Cuthbert B, Garvey M, Heinssen R, Kozak M, Pine D, et al. Research domain criteria: toward a new classification framework for research on mental disorders. Am J Psychiat 2010;167:748-51.

[25] Lilienfeld SO, Treadway MT. Clashing diagnostic approaches: DSM-ICD versus RDoC. Annu Rev Clin Psychol 2016;12:435-63.

[26] Zachar P, Stoyanov DS, Aragona M, Jablensky A, editors. Alternative perspectives on psychiatric validation: DSM, ICD, RDoC, and beyond. OUP Oxford; 2014 